tradition such as building is one of transition of quite a different order from anything it has experienced before. Nearly the whole basis of its traditional knowledge has ceased to exist or has so changed as to be scarcely recognisable. Only by intensive co-operation between practitioner and scientific worker can the necessary readjustments be made, for it is not possible to await the wasteful type of development resulting from 'trial and error' on a full scale.

Dr. Stradling concluded by saying: "What is true of building is probably true of many other industries. The problem of national readjustment is urgent and instead of making an attempt to hold up scientific research on the excuse that science has proceeded too fast and too far, the opposite is really the absolute necessity of existence. The 'clock cannot be put back' and we have had scientific work with us sufficiently long to have produced a transitional period of appalling intensity and thus the only way is forward."

Copies of the "Physics in Industry" lectures can be obtained from the Institute of Physics, 1, Lowther Gardens, Exhibition Road, London, S.W.7.

\title{
Megalithic Work in Assam
}

$\mathrm{D}$ R. J.H. HUTTON, in discussing megalithic work in Assam, in a paper read on September 11 before Section $H$ (Anthropology) at the Leicester meeting of the British Association, stated that it is important not only as bearing on the cultural and racial relations between Assam and the adjoining regions, but also on the whole question of Indian pre-history and cultural and racial relations with the Mediterranean and with Oceania. Megalithic work in Assam, and probably throughout India, has definite assoeiations with the dead and with their post-mortem future. At the same time it is, at any rate in Assam, definitely phallic in certain aspects and constitutes a fertility cult of the dead.

The idea of life as a finite material substance, limited in quantity, and passing, when the body dies, into the crops as a fertilising agent and thence in a recurrent cycle to beasts and men, is common in Assam. This conception led to the practice of providing receptacles for the life substance after the death of the body, in the shape of wooden or stone statues, generally, though not always, in the form of rough stone monuments, sometimes phallic in shape.

The Dinapur monoliths are similar in design to the wooden emblems used at a fertility ceremony by the Angami Nagas, who, however, use simple menhirs differing merely in size to represent the two sexes, or to house their life matter. The prehistoric mortuary urns of the North Cachar Hills sites are in some cases definitely male or female in form, suggesting the stone cists still used by the Konyak Nagas, which take the form of the sex of the individual whose skull is found within, the life matter being accommodated immediately after death in a wooden statue pending the removal of the head from the corpse when putrefaction is fairly advanced.

Many similar customs were reported, and the theory was advanced by Dr. Hutton that they are associated with a conception of life as a material and finite substance, a theory logically leading to head hunting, cannibalism and human sacrifice as means of obtaining life matter. The first conception of life is likely to have arisen from an attempt to understand death and the obvious, but by no means easily explicable, difference between a living man and a corpse. Life would naturally be regarded as a concrete and finite substance by savages to whom abstractions are foreign, and hence follows a wide field of speculation. On one hand, it has led to human sacrifice and similar means of obtaining life matter; on the other, to the Vedantic philosophy, which regards the body as a mere shell to house the soul, and only one of many such shells. It may be that this philosophy of life originated in the pre-Aryan civilisation of India, which was probably of Mediterranean or Syrian origin.

\section{Synthetic Estrogenic Compounds}

$\mathrm{S}^{\mathrm{P}}$ EAKING at a diseussion on hormones at a meeting of Section B (Chemistry) of the British Association on September 8, Prof. F. Kögl foreshadowed the importance of a paper to be read by a subsequent speaker on the significance of synthetic cestrogenic compounds. Prof. Kögl was referring to the oat shoot bending test for auxin. He stated that until comparatively recently this test was regarded as specific for this compound; but he now felt less positive concerning this in view of the picking of the restrus lock with a skeleton key.

The fact that the complicated œstrus reaction, with its vaginal and uterine phases, can be induced by so relatively simple a compound as 1 -keto-1:2: $3: 4$-tetrahydrophenanthrene was first demonstrated by Cook, Dodds and Hewett ${ }^{1}$. It was later shown in conjunction with Greenwood of Edinburgh, that this compound is capable of causing the feathers of the capon to revert from male to female. By this test they would appear to have demonstrated that the lock had been really opened, and not merely forced. Furthermore, a series of other compounds was added to the list.

Another very active compound is the 9:10dihydroxy - 9: 10 - di - $n$ - butyl - $9: 10$ - dihydro $1: 2: 5: 6$-dibenzanthracene. This was found to be many times more active than the keto-phenanthrene derivative, and to have an activity approaching that of the naturally occurring hormones. The similarity of the molecule of this compound to that of certain of the carcinogenic hydrocarbons led to the investigation of these substances from the point of view of œstrus production. It was found that two of these carcinogenic hydrocarbons, namely, $1: 2$. benzpyrene and 5 : 6-cyclopenteno-1 : 2-benzanthracene, possess the power not only of inducing carcinoma, but also of inducing cestrus. As pointed out by Cook and Dodds ${ }^{2}$, there is no evidence that carcinogenic compounds can arise from œstrin in the body.

Another observation difficult of interpretation was made when it was shown that calciferol, ergosterol 